\title{
Cause-of-death distributions and mortality trends in Turkey between 2009 and 2017
}

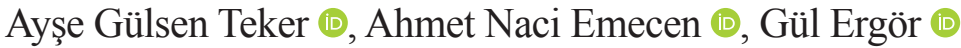

Department of Public Health, Epidemiology Subsection, Dokuz Eylül University School of Medicine, İzmir, Turkey

Background: Making the right decisions in the field of public health depends on the reliable recording of statistical data such as death and birth. There have been radical changes and innovations in the death registration since 2009 in Turkey to improve reporting.

Aims: To examine the distribution and the trend of causes of death between the years 2009 and 2017 in Turkey.

Study Design: Descriptive study.

Methods: In this study, the causes of death were evaluated in three groups used in the Global Burden of Disease study. Group I included infectious, maternal, perinatal, and nutritional conditions; group II included noncommunicable diseases; and group III included injuries. Age-standardized mortality rates were calculated per 100,000 according to age, sex, and cause of death. Joinpoint regression was used to evaluate the trend in mortality rates. In addition, the leading causes of death were also determined.

Results: In total, age-standardized mortality rates increased significantly on average annually ( $1.5 \%$ per year). When the trends of causes of death were examined according to gender, there was a significant increase in deaths from group I in both genders and a significant increase in deaths from group III in males, whereas there was no statistically significant change in deaths from group II between 2009 and 2017.

Conclusion: A significant quantitative improvement in death registration was seen in Turkey between the years 2009 and 2017. This is due to the increase in the number of reported deaths. The change in the distribution of causes of death is noteworthy. This research can provide the basis for further researches that will examine the change in causes of death.
Making the right decisions in the field of public health depends on the reliable recording of statistical data such as death and birth. Regular, frequent, and timely recording and evaluation of vital statistical records are critical not only in the healthcare decision-making process but also in social, economic, legal, and human rights issues. ${ }^{1}$ It is also important for comparing the health systems of countries or for comparing health system related current data of the same country with data from previous years.

The death recording in Turkey has been carried out since 1931. The death records at the national level are collected and presented annually by the Turkish Statistical Institute (TURKSTAT). To increase death registration and improve the quality, radical changes and innovations have been made in the system since 2009. The two basic changes are that previous deaths in provincial and district centers were recorded in the registration system, whereas in the new system, deaths in the entire country, including those in villages, are recorded, and the International Classification of Diseases, Tenth Revision (ICD-10) started being used in the classification of causes of death.
The death certificate for each death is filled by the physician in charge. This form includes the place and date of death as well as demographic data of the deceased, the main cause of death, and other causes that are not relevant to this main cause but are associated with death. The underlying cause of death in the form is recorded as the main cause of death in the cause of death classification. It is the conditions, an accident, or a violent act that results in illness or injury or fatal injury, leading to the onset of disease conditions that directly cause death. Contributing causes are diseases or conditions that are not part of the chain of events leading to death but have contributed to death according to the person filling out the form. If the death has occurred in the hospital, it is reported by the responsible physician, and if the death has occurred at home or elsewhere, it is reported by the family physician, the municipality physician, or another designated physician. It is essential that the person reporting the death is a physician; however, another officer, headman, or military officer in the rural regions where the physician is not present can do the death registration., ${ }^{2,3}$

This research was presented as the Oral Presentation at the $3^{\text {rd }}$ International, $21^{\text {st }}$ National Public Health Congress.

Address for Correspondence: Ayşe Gülsen Teker, Department of Public Health, Epidemiology Subsection, Dokuz Eylül University School of Medicine, İzmir, Turkey e-mail: agulsenteker@hotmail.com

Received: April 28, 2020 Accepted: October 14, 2020, Available Online Date: February 26, 2021 • DOI: 10.4274/balkanmedj.galenos.2020.2020.4.200

Available at www.balkanmedicaljournal.org

ORCID iDs of the authors: A.G.T. 0000-0003-4958-007X; A.N.E. 0000-0003-3995-0591; G.E. 0000-0002-2263-7526.

Cite this article as:

Teker AG, Emecen AN, Ergör G. Cause-of-death distributions and mortality trends in Turkey between 2009 and 2017. Balkan Med J. 2021;38(2):121-126.

Copyright@Author(s) - Available online at http://balkanmedicaljournal.org/ 
Turkey has experienced a period of sociodemographic and economic change, especially since the 1970s. This change was reflected in the life expectancy, birth and mortality rates, and the distribution of causes of death, particularly since the 1970 s. $^{4-6}$ However, no comprehensive study of the causes of death has been conducted in recent years after the new death registration system.

The aim of this study is to examine the distribution and trend of causes of death between the years 2009 and 2017 in Turkey.

\section{MATERIAL AND METHODS}

\section{Data sources}

For this descriptive study, data related to deaths between the years 2009 and 2017 and the mid-year populations of these years were obtained from TURKSTAT.

\section{Classification of causes of death}

The causes of death classified according to the ICD-10 classification were in 19 groups and 211 subgroups. The causes of death were divided into three groups as in the first level classification of the Global Burden of Disease (GBD) study. ${ }^{7}$ Group I included infectious, maternal, perinatal, and nutritional conditions; group II included noncommunicable diseases (NCDs); and group III included external causes, including both intentional and unintentional injuries. Deaths for garbage/ill-defined reasons were also examined. The codes of the groups and garbage/ill-defined reasons are defined according to the World Health Organization (WHO) Global Health Estimates $2016^{8}$ specified in Appendix 1.

\section{Statistical Analysis}

Data received as excel files were transferred to $\mathrm{R}$, version 3.4.3. Although the total number of deaths in the database was $3,187,877$, a total of 10,531 records could not be analyzed owing to missing values of age, sex, and/or ICD code. The remaining 3,177,346 records were analyzed.

In the first step, crude mortality rates (CMRs) and age-specific mortality rates for women and men were calculated for each year, and then age-standardized mortality rates (ASMRs) were calculated using the standard population distribution ${ }^{9}$ of the WHO. The formulas used in the calculations are as follows:

1. $\mathrm{CMR}=$ (Total number of deaths from all causes/Number of persons in the population at mid year) $\times 100,000$.

2. Age-Specific Mortality Rate $=($ Number of deaths among age group ' $\mathrm{k}$ ' in 1 year/Number of persons at age group ' $\mathrm{k}$ ' in the population at mid year) $\times 100,000$.

3. $\mathrm{ASMR}=$ Age-specific mortality rate per $100,000 \times$ weight in the standard population.

In the second step, CMR and ASMR values were calculated separately for each year and sex of the death cause groups and garbage/ ill-defined causes of death.

In the last step, we performed joinpoint regression analysis (Joinpoint Regression Program, version 4.6.0.0; Statistical Methodology and Applications Branch, Surveillance Research
Program, National Cancer Institute, Bethesda, MD, USA) to study the trends over time to identify the time point(s) in which the trend significantly changed in the study period. The average annual percentage change (AAPC) of the ASMRs from 2009 to 2017 was calculated for the sex and the cause-of-death groups, assuming that the random errors were heteroscedastic. Ethics committee approval for the study was obtained from Ethics Committee for Non-Interventional Studies (Protocol Number: 2019/04-12).

\section{RESULTS}

According to the TURKSTAT database, 3,187,877 deaths occurred between the years 2009 and 2017 in Turkey (1,744,211 men and 1,443,355 women). Figure 1 shows the percentage distribution of causes of death by groups and gender. In the period between 2009 and 2017 , the percentage of group I causes in males increased from $5.6 \%$ to $8.9 \%$, and the percentage in females increased from $5.7 \%$ to $9.9 \%$. Group II causes decreased in males from $77.8 \%$ to $75.6 \%$ and in females from $77.1 \%$ to $75.5 \%$. Group III causes increased from $4.8 \%$ to $5.8 \%$ in males; however, they decreased slightly from $2.8 \%$ to $2.7 \%$ in females. Deaths from garbage/ill-defined causes decreased in both males and females from $11.8 \%$ to $9.7 \%$ and from $14.4 \%$ to $11.9 \%$, respectively.

The changes in CMR and ASMR among males and females and the AAPC of the ASMRs in the 9-year period between 2009 and 2017 are shown in Table 1. ASMR values among both males and females increased significantly at the end of the 9-year period. ASMR was annually increased by $1.5 \%$ in total $(1.6 \%$ in males and $1.4 \%$ in females $)(P<0.05)$.

Table 2 shows the CMR and ASMR values in males and females in 2009 and 2017 by cause-of-death groups and gender with the AAPC for ASMR values between the years 2009 and 2017. According to Table 2, an overall increase in mortality rates of group I and group III has occurred (11.8\% and 4.8\%, respectively). The mortality rates in group I and group III causes increased significantly in males ( $12.0 \%$ and $5.4 \%$, respectively); however, in females, there was a significant increase in mortality rates

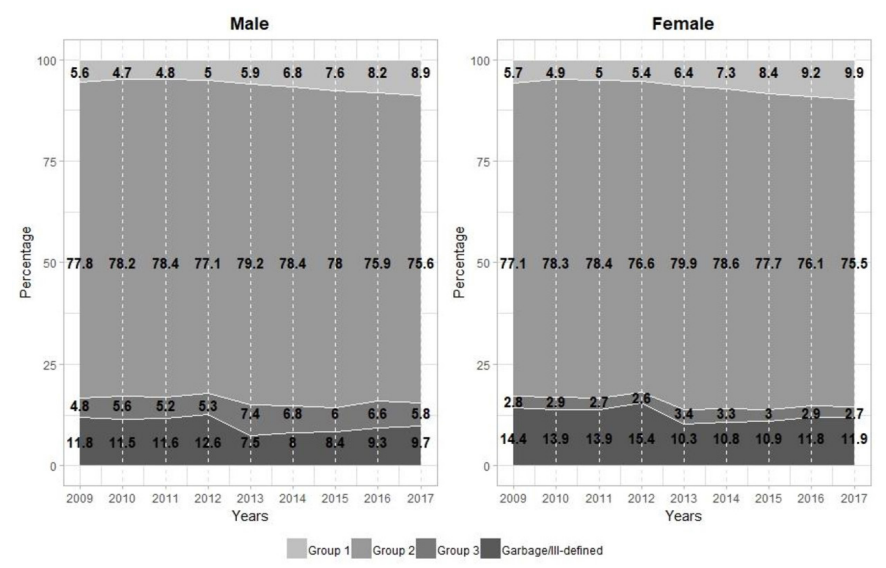

FIG. 1. The distribution of group 1, group 2, group 3, and garbage/ill-defined causes of death between 2009 and 2017 by gender. 
TABLE 1. CMR and ASMR per 100,000 by gender in 2009 and 2017 with AAPC in ASMRs between 2009 and 2017

\begin{tabular}{|c|c|c|c|c|c|}
\hline \multirow[b]{2}{*}{ Group } & \multicolumn{2}{|c|}{2009} & \multicolumn{2}{|c|}{2017} & \multirow{2}{*}{$\frac{2009-2017}{\text { AAPC }(95 \% \mathrm{CI})}$} \\
\hline & CMR & ASMR & CMR & ASMR & \\
\hline Overall & 388.45 & 455.52 & 517.34 & 491.39 & $1.5(0.7,2.4)^{*}$ \\
\hline Male & 428.52 & 567.39 & 560.78 & 614.72 & $1.6(0.7,2.5)^{*}$ \\
\hline Female & 348.02 & 362.91 & 473.71 & 388.79 & $1.4(0.6,2.3)^{*}$ \\
\hline
\end{tabular}

TABLE 2. CMR and ASMR per 100,000 by cause-of-death groups and gender in 2009 and 2017 with AAPC in ASMRs between 2009 and 2017

\begin{tabular}{|c|c|c|c|c|c|c|}
\hline & \multirow[b]{2}{*}{ Cause-of-death groups } & \multicolumn{2}{|c|}{2009} & \multicolumn{2}{|c|}{2017} & \multirow{2}{*}{$\frac{2009-2017}{\text { AAPC }(95 \% \mathrm{CI})}$} \\
\hline & & CMR & ASMR & CMR & ASMR & \\
\hline \multirow[t]{3}{*}{ Overall } & Group I & 21.90 & 24.16 & 48.47 & 47.25 & $11.8(8.6,15.1)^{*}$ \\
\hline & Group III & 15.09 & 16.38 & 22.64 & 21.93 & $4.8(0.2,9.6)^{*}$ \\
\hline & Garbage/ill-defined & 50.39 & 61.86 & 55.52 & 52.07 & $-2.8(-6.2,0.6)$ \\
\hline & Group III & 20.48 & 23.14 & 32.75 & 33.25 & $5.4(0.5,10.6)^{*}$ \\
\hline & Garbage/ill-defined & 50.53 & 72.14 & 54.53 & 61.22 & $-2.9(-6.5,1.0)$ \\
\hline \multirow[t]{2}{*}{ Female } & Group I & 19.90 & 21.00 & 47.07 & 40.54 & $11.8(8.5,15.1)^{*}$ \\
\hline & Group II & 268.24 & 278.71 & 357.65 & 292.70 & $1.1(-0.1,2.3)$ \\
\hline
\end{tabular}

$* P<0.05$.

AAPC, average annual percentage change; ASMR, age-standardized mortality rate; CI, confidence interval; CMR, crude mortality rate.

only in group I (11.8\%). No significant change was observed in the mortality rates in group II and garbage/ill-defined causes of death.

When the increase in deaths due to group I causes was examined in more detail, it was observed that pneumonia was the main reason for the change. Whereas the number of deaths due to pneumonia in 2009 was 2,784 , it increased to 18,484 in 2017 ; whereas $17.7 \%$ of the causes of death in group I in 2009 was pneumonia, this rate was $47.4 \%$ in 2017 . The frequencies of all the other leading communicable, maternal, perinatal, and nutritional conditions-related death causes (Group I) have decreased in 2017. In addition, 84\% of the deaths due to pneumonia were observed in persons aged $\geq$ 65 years.

When a closer look was taken at the increase in deaths in group III, it was determined that the number increased from 10,869 in 2009 to 18,183 in 2017 . This situation is not related to a specific cause of death. There has been no change in the ranking of nontransport accidents, transport accidents, and intentional self-harm, which are the three most common causes of death in group III. There was also no significant change in the frequency of these causes in group III $(46.3 \%, 35.8 \%$, and $9.6 \%$ to $46.1 \%$, $34.7 \%$, and $9.7 \%$, respectively); however, their numbers have increased.
Table 3 shows the leading causes of death in males and females. Ischemic heart diseases and malignant neoplasms, which were ranked in the top two in 2009 in males, have remained in place in 2017 (from $15.3 \%$ to $16.4 \%$ and from $10.2 \%$ to $9.4 \%$, respectively). Whereas the garbage/ill-defined causes (4.7\%) and hypertensive diseases (3\%) listed in 2009 were not in the list in 2017, pneumonia (4.2\%) and nontransport accidents $(2.8 \%)$ were added to the list. Whereas cerebrovascular diseases (13.2\%), the most common cause of death in females in 2009 , were replaced by ischemic heart disease (15\%) in 2017, the top three leading causes of death in females did not change in 2009 and 2017. However, the garbage/ill-defined causes $(4.7 \%)$ and respiratory and intrathoracic organ cancers $(2.1 \%)$ that were listed in 2009 were not in the list in 2017 . Instead of these causes, pneumonia $(4.7 \%)$ and Alzheimer's disease (4.4\%) were added to the leading causes of death in 2017.

Although the causes of death that were newly added to the list are not detailed in Table 3, it was found that the number of deaths due to nontransport accidents increased from 5,125 to 9,054 between 2009 and 2017. The most common reasons were falls (40\%), accidental poisonings $(12 \%)$, and accidental exposure to other and unspecified factors $(16 \%)$. Deaths due to Alzheimer's disease increased from 3,844 to 13,743 . The increase in pneumonia-related mortality has been mentioned previously. 
TABLE 3. First 10 leading causes of death with percentages by gender in 2009 and 2017

\begin{tabular}{|c|c|c|c|c|c|c|c|}
\hline \multirow[b]{2}{*}{ Gender } & \multirow[b]{2}{*}{ Rank } & \multicolumn{3}{|l|}{2009} & \multicolumn{3}{|l|}{2017} \\
\hline & & ICD-10 code & Cause of death & $\%$ & ICD-10 code & Cause of death & $\%$ \\
\hline \multirow[t]{11}{*}{ Male } & 1 & I20-I25 & Ischemic heart diseases & 15.3 & I20-I25 & Ischemic heart diseases & 16.4 \\
\hline & 2 & C30-C39 & $\begin{array}{l}\text { Malignant neoplasms of respiratory and intrathorac- } \\
\text { ic organs }\end{array}$ & -10.2 & C30-C39 & $\begin{array}{l}\text { Malignant neoplasms of respiratory and in- } \\
\text { trathoracic organs }\end{array}$ & -9.4 \\
\hline & 3 & I60-I69 & Cerebrovascular diseases & 8.7 & I30-I52 & Other forms of heart disease & 8.4 \\
\hline & 4 & I30-I52 & Other forms of heart disease & 8.0 & I60-I69 & Cerebrovascular diseases & 7.5 \\
\hline & 5 & J40-J47 & Chronic lower respiratory diseases & 7.5 & J40-J47 & Chronic lower respiratory diseases & 7.3 \\
\hline & 6 & $\mathrm{C} 15-\mathrm{C} 26$ & Malignant neoplasms of digestive organs & 6.3 & $\mathrm{C} 15-\mathrm{C} 26$ & Malignant neoplasms of digestive organs & 6.5 \\
\hline & 7 & R00-R99 & $\begin{array}{l}\text { Symptoms, signs, and abnormal clinical and labora- } \\
\text { tory findings not classified elsewhere }\end{array}$ & -4.7 & J12-J18 & Pneumonia & 4.2 \\
\hline & 8 & E10-E14 & Diabetes mellitus & 4.0 & E10-E14 & Diabetes mellitus & 3.0 \\
\hline & 9 & I10-I15 & Hypertensive diseases & 3.0 & N17-N19 & Renal failure & 3.0 \\
\hline & \multirow[t]{2}{*}{10} & \multirow[t]{2}{*}{ N17-N19 } & Renal failure & 2.2 & \multicolumn{2}{|c|}{$\begin{array}{l}\text { W } 00 \text { - X } 59 \text {, Nontransport accidents } \\
\text { Y } 86\end{array}$} & 2.8 \\
\hline & & & Other remaining causes & 30.1 & & Other remaining causes & 31.5 \\
\hline \multirow[t]{11}{*}{ Female } & 1 & I60-I69 & Cerebrovascular diseases & 13.2 & I20-I25 & Ischemic heart diseases & 15.0 \\
\hline & 2 & I20-I25 & Ischemic heart diseases & 12.6 & I30-I52 & Other forms of heart disease & 11.1 \\
\hline & 3 & I30-I52 & Other forms of heart disease & 10.9 & I60-I69 & Cerebrovascular diseases & 10.9 \\
\hline & 4 & E10-E14 & Diabetes mellitus & 7.2 & J40-J47 & Chronic lower respiratory diseases & 5.3 \\
\hline & 5 & I10-I15 & Hypertensive diseases & 6.1 & $\mathrm{C} 15-\mathrm{C} 26$ & Malignant neoplasms of digestive organs & 5.0 \\
\hline & 6 & $\mathrm{C} 15-\mathrm{C} 26$ & Malignant neoplasms of digestive organs & 5.2 & I10-I15 & Hypertensive diseases & 4.8 \\
\hline & 7 & R00-R99 & $\begin{array}{l}\text { Symptoms, signs, and abnormal clinical and labora- } \\
\text { tory findings not classified elsewhere }\end{array}$ & -4.7 & J12-J18 & Pneumonia & 4.7 \\
\hline & 8 & J40-J47 & Chronic lower respiratory Diseases & 4.7 & E10-E14 & Diabetes mellitus & 4.7 \\
\hline & 9 & N17-N19 & Renal failure & 2.6 & G30 & Alzheimer's disease & 4.4 \\
\hline & \multirow[t]{2}{*}{10} & \multirow[t]{2}{*}{$\mathrm{C} 30-\mathrm{C} 39$} & $\begin{array}{l}\text { Malignant neoplasms of respiratory and intrathorac- } \\
\text { ic organs }\end{array}$ & -2.1 & N17-N19 & Renal failure & 3.7 \\
\hline & & & Other remaining causes & 30.6 & & Other remaining causes & 30.4 \\
\hline
\end{tabular}

\section{DISCUSSION}

In this study, ASMRs increased significantly by, on average, $1.5 \%$ per year between 2009 and 2017. Moreover, the number of expected deaths was 415,900 in 2010 in Turkey; in fact, there were 295,501 deaths reported in that year, showing that records from outside of the provinces and districts were missing. ${ }^{10}$ Whereas the expected number of deaths was 455,400 in 2016 , there were 420,189 deaths reported. ${ }^{11-13}$ This change in death numbers and ASMR is not due to an increase in the number of deaths but due to an increase in the number of reported deaths. This indicates a notable quantitative improvement in death registration in the period of 9 years.

The main finding of this study was the increase in deaths caused by group I and group III, whereas there was no statistically significant change in deaths from NCDs (group II) between 2009 and 2017.

Many studies conducted in recent years have shown that a significant decrease occurred in cardiovascular mortality. In a study conducted by Dinc et al. ${ }^{14}$ it has been found that the decrease since 1994 has reached $7.9 \%$ in males and $4.4 \%$ in females between 2004 and 2008. A similar decrease has been revealed in many countries such as the United States, Western Europe, Ireland, Sweden, England and Wales, Italy, and Poland. In modeling studies, this situation was mainly attributed to the reduction of the risk factors and effective treatments. ${ }^{14-22}$ This decrease in NCD-related deaths seen in previous studies does not seem to continue during 2009-2017; cardiovascular diseases continue to constitute a significant morbidity and mortality burden. Today in Turkey, the structural problems on the prevention of NCDs, early diagnosis, and follow-up issues could not be resolved, such as integration of primary health care services into the management of chronic diseases and lack of coordination between health institutions. Effective control strategies and programs are not implemented nationally. ${ }^{5}$

In the GBD study, deaths due to infection of the lower respiratory tract were estimated to be increased by $38.3 \%$ in Turkey in 
$2017 .{ }^{23}$ In accordance with this, an increase in mortality rates related to the group I causes was detected in this study. In addition, it was found that the major cause of the increase in the causes of death in group I was pneumonia. A significant part of these deaths occurred in people aged $\geq 65$ years. The proportion of people aged $\geq 65$ years in Turkey is rising steadily in recent years. ${ }^{24}$ Whereas $64.6 \%$ of all deaths have occurred in people aged $\geq 65$ years in 2009 , it has increased to $70.7 \%$ in 2017. ${ }^{12,13}$ As another reason, the Sentinel Severe Acute Respiratory Tract Infections Surveillance has been initiated in Turkey since 2015. ${ }^{25}$ This may have increased the coding of deaths caused by pneumonia.

Another notable finding in this study was that Alzheimer's disease was listed among the leading causes of death. The changing demography and the increasing number of the elderly population make the healthcare needs of this special group necessary for Turkey.

In this study, it was observed that the rate of deaths due to group III conditions in men increased annually by $5 \%$ in the period of 9 years. This is similar to the findings in the GBD study. ${ }^{26}$ In group III, deaths were mostly related to nontransport accidents. These accidents are the result of a combination of multiple risk factors, and there is no single simple method to avoid these accidents. Risk factors should be identified individually, and multifactorial protection strategies should be planned..$^{27,28}$

The strengths of this study were the inclusion of the period of 9 years after the transition to the new system and the evaluation of all deaths, which are reported in this period in Turkey. In addition, the change in the causes of deaths over the study period is presented with AAPC, which is a summary measure of the trend over the fixed interval, using joinpoint regression. Evaluating AAPCs made different groups comparable with the change in trends for the same period. As a limitation, the effect of the improvement in death records on the distribution of causes of death could not be determined in this study. Improvement in death records may have affected both ASMR and the distribution of causes of death.

In conclusion, a significant quantitative improvement in death registration was seen in Turkey between 2009 and 2017. In addition to quantitative improvement in death registration, changes in the pattern of causes were also observed. The change in the distribution of causes of death is noteworthy. This overall analysis for the whole country can provide the basis for further research that will examine the change in causes of death more in depth.

Ethics Committee Approval: Ethics committee approval for the study was obtained from Dokuz Eylül University Medical Faculty Ethics Committee for Non-Interventional Studies (Protocol Number: 2019/04-12).

\section{Patient Consent for Publication: N/A}

Data-sharing Statement: N/A

Author Contributions: Concept - A.G.T., A.N.E., G.E.; Design - A.G.T., A.N.E., G.E.; Supervision - A.G.T., A.N.E., G.E.; Resources - A.G.T., A.N.E., G.E.; Materials - A.G.T., A.N.E., G.E.; Data Collection and/or Processing - A.G.T., A.N.E., G.E.; Analysis and/or
Interpretation - A.G.T., A.N.E., G.E.; Literature Review - A.G.T., A.N.E., G.E.; Writing A.G.T., A.N.E., G.E.; Critical Review - A.G.T., A.N.E., G.E.

Conflict of Interest: The authors have no conflicts of interest to declare.

Funding: The authors declared that this study had received no financial support.

\section{REFERENCES}

1. AbouZahr C, Cleland J, Coullare F, et al. The way forward. The Lancet 2007; DOI:10.1016/S0140-6736(07)61310-5. [Crossref]

2. Bakar C, Cevizci S. Data for death registration system: an accuracy evaluation of the data of death causes in Canakkale, Turkey. Nobel Med. 2016;12(3):39-46.

3. Ozdemir R, Rao C, Ocek Z, Horasan GD. Reliable mortality statistics for Turkey: Are we there yet? BMC Public Health. 2015;15:545. [Crossref]

4. Hacettepe University Institute of Population Studies. Turkey demographic and health survey, 2013, Hacettepe University Institute of Population Studies. Ankara, Turkey: T.R. Ministry of Development and TUBITAK; 2014. Available from: http://www. hips.hacettepe.edu.tr/tnsa2013/rapor/TNSA_2013_ana_rapor.pdf (last accessed 2 January 2019).

5. Ozdemir R, Horasa GD, Rao C, Sozmen MK, Unal B. An evaluation of cause-ofdeath trends from recent decades based on registered deaths in Turkey. Public Health. 2017;151:121-130. [Crossref]

6. Turkish Statistical Institute. Available from: http://www.tuik.gov.tr/UstMenu. do?metod=temelist (last accessed on 3 January 2019).

7. Global Burden of Disease Collaborative Network. Global Burden of Disease Study 2017 (GBD 2017) Covariates 1980-2017. Seattle, United States: Institute for Health Metrics and Evaluation (IHME), 2018.

8. World Health Organization. WHO methods and data sources for country-level causes of death 2000-2016 (Global Health Estimates Technical Paper WHO/HIS/IER/ GHE/2018.3). Geneva: World Health Organization, 2018. (available from: http://terrance.who.int/mediacentre/data/ghe/GlobalCOD_method_2000_2016.pdf?ua=1 last accessed on 3 January 2019)

9. Ahmad OB, Boschi-Pinto C, Lopez AD, Murray CJ, Lozano R, Inoue M. Age standardization of rates: a new WHO standard. Geneva: World Health Organization; 2001.

10. Bakar C, Oymak S, Maral I. Turkey's Epidemiological and Demographic Transitions: 1931-2013. Balkan Med J. 2017;34(4):323-334. [Crossref]

11. Global Health Estimates 2016: Deaths by Cause, Age, Sex, by Country and by Region, 2000-2016. Geneva, World Health Organization; 2018.

12. Turkish Statistical Institute. Available from: http://www.tuik.gov.tr/PreHaberBultenleri.do?id=10712 (last accessed on 3 January 2019).

13. Turkish Statistical Institute. Available from: http://www.tuik.gov.tr/PdfGetir do?id=27620 (last accessed on 3 January 2019).

14. Dinc G, Sözmen K, Gerçeklioğlu G, Arık H, Critchley J, Ünal B. Decreasing trends in cardiovascular mortality in Turkey between 1988 and 2008. BMC Public Health. 2013;30;13:896. [Crossref]

15. Ford ES, Ajani UA, Croft JB, et al. Explaining the decrease in U.S. deaths from coronary disease, 1980-2000. N Engl J Med. 2007;356(23):2388-2398. [Crossref]

16. Müller-Nordhorn J, Binting S, Roll S, Willich SN. An update on regional variation in cardiovascular mortality within Europe. Eur Heart J. 2008;29(10):1316-1326. [Crossref]

17. Bennett K, Zubair K, Unal B, Shelley E, Critchley J, Perry I. Explaining the recent decrease in coronary heart disease mortality rates in Ireland, 1985-2000. J Epidemiol Community Health. 2006;60(4):322-327. [Crossref]

18. Bjorck L, Rosengren A, Bennett K, Lappas G, Capewell S. Modelling the decreasing coronary heart disease mortality in Sweden between 1986 and 2002. Eur Heart J. 2009;30(9):1046-1056. [Crossref]

19. Unal B, Critchley JA, Capewell S. Circulation: explaining the decline in coronary heart disease mortality in England and Wales between 1981 and 2000. Circulation. 2004;109(9):1101-1107. [Crossref]

20. Palmieri L, Bennett K, Giampaoli S, Capewell S. Explaining the decrease in coronary heart disease mortality in Italy between 1980 and 2000. Am J Public Health. 2010;100(4):684-692. [Crossref] 
21. Bandosz P, O'Flaherty M, Drygas W, et al. Decline in mortality from coronary heart disease in Poland after socioeconomic transformation: modelling study. BMJ 2012;344:d8136. [Crossref]

22. Unal B, Sözmen K, Arık H, et al. Explaining the decline in coronary heart disease mortality in Turkey between 1995 and 2008. BMC Public Health. 2013;13:1135. [Crossref]

23. IHME Institute for Health Metrics and Evaluation. Turkey. Available from: http:// www.healthdata.org/turkey (last accessed on 14 February 2019).

24. Turkish Statistical Institute. Available from: http://www.tuik.gov.tr/PreHaberBultenleri.do?id=27595 (last accessed on 3 January 2019).
25. Civelek-Eser F, Tütüncü EE, Haykır-Solay A, et al. [Evaluation of patients diagnosed with severe acute respiratory tract infection: 2015-2016 influenza season]. Klimik Derg. 2017;30(3):114-119. [Crossref]

26. GBD 2017 Causes of Death Collaborators. Global, regional, and national agesex-specific mortality for 282 causes of death in 195 countries and territories, 19802017: a systematic analysis for the global burden of disease study 2017. Lancet. 2018;392(10159):1736-1788. [Crossref]

27. Ambrose AF, Cruz L, Paul G. Falls and fractures: a systematic approach to screening and prevention. Maturitas. 2015;82(1):85-93. [Crossref]

28. Callis N. Falls prevention: Identification of predictive fall risk factors. Appl Nurs Res. 2016;29:53-58. [Crossref] 
APPENDIX 1. The cause-of-death groups and ICD-10 codes

Cause of death

ICD-10 codes

Group I: communicable, maternal, perinatal, and nutritional con- A00-B99, D50-D53, D64.9, E00-E02, E40 E46, G00-G04, G14, H65- H66, J00-J22, N70-N73, ditions

O00-O99, P00-P96, U04

Group II: noncommunicable diseases

C00-C97, D00-D48, D55-D64 (minus D64.9), D65-D89, E03-E07, E10-E16, E20-E34, E65-E88, F01-F99, G06-G99 (minus G14), H00-H61, H68-H93, I00-I99, J30-J98, K00- K92, L00- L98, M00-M99, N00-N64, N75-N98, Q00-Q99, X41-X42, X44, X45, R95

Group III: injuries

V01-Y89 (minus X41-X42, X44, X45)

Garbage/ill-defined causes of death

I47.2, I49.0, I46, I50, I51.4, I51.5, I51.6, I51.9, I70.9, R00-R99 (minus R95)

ICD-10, International Classification of Diseases, Tenth Revision. 